\title{
秎 \\ GESTÃO ESPORTIVA: A IMPORTÂNCIA DA GOVERNANÇA CORPORATIVA NO CENÁRIO BRASILEIRO
}

\author{
SPORT MANAGEMENT: THE IMPORTANCE OF THE CORPORATIVE \\ GOVERNANCE IN THE BRAZILIAN SCENARIO
}

\author{
GESTIÓN DEPORTIVA: LA IMPORTANCIA DE LA GOBERNANZA \\ CORPORATIVA EN EL ESCENARIO BRASILEÑO
}

\section{Mateus David Finco*}

Resumo: A gestão esportiva no Brasil é um tema de grande importância para o desenvolvimento de diversas modalidades olímpicas e não olímpicas. O objetivo deste estudo foi de avaliar o nível de governança corporativa da Confederação Brasileira de Hóquei sobre Grama e Indoor (CBHG), avaliando os seguintes aspectos: estatuto, assembleia geral e estrutura organizacional. Como metodologia foi empregado um delineamento qualitativo envolvendo coleta de dados documentais e entrevista com o gestor da entidade. Como resultados deste estudo, foi possível averiguar que os itens estatuto e contrato social, assembleia geral e estrutura organizacional, papéis e responsabilidade necessitam de ações específicas para elevar o índice de boa governança na Confederação. Conclui-se que a entidade pode primar pelos princípios da governança corporativa para que todas as áreas de desenvolvimento da gestão esportiva sejam potencializadas e cada vez mais qualificadas.

Palavra-chave: Governança Corporativa. Gestão Esportiva. Estrutura Organizacional. Esportes. Hóquei sobre Grama.

\begin{abstract}
The sport management in Brazil is a topic of great importance for the development of several Olympic and non-Olympic modalities. This research aims to evaluate the level of corporate management adopted by the Brazilian Indoor and Field Hockey Confederation, assessing the following aspects: Statute, Organizational Structure and General Assembly. A method of quantitative anyalisis was applied, involving the collection of document data and interview with the entity manager. As a result of this study, it was possible to verify that the itens Statutes; General Assembly and Organizational Structure; papers and liability require specific actions to increase the confederation levels of good management. Finally, it can be said that the entity may focus on the principles of corporate management so that all areas of devolopment of sport management can be boosted and more and more enhanced.
\end{abstract}

\footnotetext{
*Graduado em Licenciatura Plena em Educação Física, Mestre em Ciências do Movimento Humano e Doutor em Informática na Educação pela Universidade Federal do Rio Grande do Sul. Atualmente é Professor da Universidade Federal da Paraíba. (mateusfinco@gmail.com)
} 
Keywords: Corporate Governance. Sports Management. Organizational Structure. Sports. Field Hockey.

Resumen: La gestión deportiva en Brasil es un tema de gran importancia para el desarrollo de las modalidades olímpicas y no olímpicas. El objetivo de este estudio fue de evaluar el nivel de gobernanza corporativa de la Confederación Brasileña de Hockey sobre Césped y Sala (CBHG), evaluando los siguientes aspectos: Estatuto, Asamblea General y Estructura Organizacional. Como metodología fue empleado un delineamiento cualitativo que implica colecta de datos documentales y entrevista con el gestor de la entidad. Como resultados de este estudio fue posible averiguar que los artículos Estatuto e Contracto Social; Asamblea General e Estructura Organizacional, papeles e responsabilidad necesitan de acciones específicas para elevar el índice de buena gobernanza en la Confederación. Se concluye que la organización deportiva puede sobresalir con los principios de la gobernanza corporativa, para que todas las áreas de desarrollo de gestión deportiva sean potencializadas y cada vez mas calificadas.

Palabras clave: Gobernanza Corporativa. Gestión Deportiva. Estructura Organizacional. Deportes. Hockey sobre Césped.

\section{Introdução}

A gestão esportiva no Brasil é um assunto de grande importância para o desenvolvimento de diversas modalidades olímpicas e não olímpicas. Precisamente, as modalidades olímpicas necessitam de um planejamento que propenda principalmente para investimentos e de um planejamento adequado, para que os ciclos olímpicos e a administração esportiva possam conceder um ambiente favorável. Desta maneira, contribui-se para que resultados expressivos (em nível nacional e internacional) e a popularidade dos esportes sejam uma constante realidade. Assim, as modalidades olímpicas poderão fruir de novos stakeholders para um consequente firmamento da modalidade no cenário nacional.

Por conseguinte, investimentos em diversas áreas precisam ser cuidadosamente elaborados, planejados e propostos, tais como marketing, finanças, gestão de pessoas, planejamento estratégico, entre outros, para que a governança corporativa possa estar alinhada e servir como uma engrenagem para o desenvolvimento da gestão do esporte. Destarte, também é de suma importância que um trabalho interdisciplinar seja destacado para que se produzam novos conhecimentos e consequentemente novas experiências positivas na administração esportiva.

Esse processo requer sempre uma manutenção e análise constantes de todas as ações realizadas dentro da Organização Esportiva Olímpica, pois renovação e modernização das atividades dentro da instituição são motivos de sucesso e de uma boa gestão, permitindo que inovações e um contínuo questionamento das práticas de governança sejam condicionantes de um amadurecimento da OEO para a sua própria atuação. 
Como o retrato nacional atual se encontra assolado por denúncias de corrupção, falta de credibilidade política, problemas econômicos e sociais, torna-se imprescindível que as OEOs possam trazer bons princípios de governança para as suas práticas administrativas, possibilitando uma maior credibilidade por parte dos stakeholders e permitindo o incremento da confiança primordialmente entre as relações estabelecidas.

Isto posto, problemas de ordem administrativa podem ser substituídos por exemplos a serem seguidos em mandatos das gestões posteriores, tais como novos mecanismos de atuação da OEO, que podem se tornar referência e consolidar a boa governança.

A transparência é requisito essencial para que todas as práticas econômicas sejam divulgadas, tratando de apresentar os gastos e os investimentos da gestão em equipes nacionais, fomento do esporte e aquisição de equipamentos e espaços físicos para a prática da modalidade esportiva, ou seja, o bom emprego dos recursos financeiros, sejam eles de ordem pública ou privada, deve estar presente nas prestações de contas para todos os interessados, devendo tais informações serem disponibilizadas nos canais de comunicação da entidade. Desta forma, fortalece-se a gestão empresarial e também a credibilidade, tão necessária hoje em dia para que se possa modificar a realidade nacional.

Este estudo apresenta o caso da Confederação Brasileira de Hóquei sobre Grama e Indoor ( $\mathrm{CBHG})$, que, mesmo se tratando de uma entidade relativamente jovem em nosso território nacional, vem aplicando os princípios da governança corporativa para que todas as áreas de desenvolvimento de uma gestão sejam atendidas e paulatinamente qualificadas e melhoradas. Dentro dessa perspectiva, este estudo destaca a implementação de um projeto prático para a melhoria do índice de maturidade da entidade, tendo como objetivo qualificar três temas específicos de governança: estatuto e contrato social; assembleia geral; e estrutura organizacional, papéis e responsabilidades.

A estrutura deste artigo conta com a seção 1 abordando a conceituação da governança corporativa, assim como um breve histórico da Confederação Brasileira de Hóquei sobre Grama e Indoor. A seção 2 apresenta os benefícios práticos de se ter uma boa governança para a CBHG, fazendo uma análise sobre possíveis melhorias e o desenvolvimento da governança dentro da Organização Esportiva Olímpica (OEO). A seção 3 aborda o grau de maturidade da governança, por meio da qual são relatadas as experiências práticas da mensuração do índice de maturidade da governança da OEO. Já a seção 4 traz a abordagem do projeto prático deste estudo para melhorias no índice de maturidade da OEO, seguida da conclusão da realização deste estudo.

\section{Governança corporativa: conceituação e histórico}

Governança corporativa é o sistema pelo qual as empresas e demais organizações são dirigidas, monitoradas e incentivadas, envolvendo os relacionamentos entre sócios, conselho de 
administração, diretoria, órgãos de fiscalização e controle, assim como as demais partes interessadas (IBGC, 2017). As boas práticas de governança corporativa convertem princípios básicos em recomendações objetivas, alinhando interesses com a finalidade de preservar e otimizar o valor econômico de longo prazo da organização, facilitando seu acesso a recursos e contribuindo para a qualidade da gestão da organização, sua longevidade e o bem comum.

De acordo com Marques (2007),

O conceito de governança corporativa está, portanto, relacionado com a accountability, cujas exigências diferem consoante a natureza da organização em causa. O termo é vantajoso para agregar um número de processos destinados a assegurar a accountability dentro das entidades públicas, tendo, numa fase inicial, a sua popularidade ocorrida no contexto do setor privado (MARQUES, 2007, p. 1).

De acordo com Grün (2005), a evolução da governança corporativa no Brasil está intimamente associada ao coroamento dos instrumentos pontuais de imposição da lógica financeira nas sociedades modernas. $\mathrm{O}$ autor preconiza que o blue-print original da governança corporativa, ao se espraiar pelo país, tem-se alterado sensivelmente mediante as interações sociais dos diversos grupos de atores que dela se apropriam.

Já para Barros e Silveira (2008), a governança corporativa tem a seguinte característica:

A governança corporativa pode ser vista como o conjunto de mecanismos que visam a aumentar a probabilidade de os fornecedores de recursos garantirem para si o retorno sobre seu investimento. O risco de os recursos dos investidores não serem bem empregados ou serem desviados decorre fundamentalmente da existência de uma situação de separação entre propriedade e controle, em que as pessoas que fornecem capital não participam diretamente das decisões corporativas. Esta situação ocorre na maioria das grandes corporações, onde os gestores, executivos profissionais em companhias com estrutura de propriedade pulverizada ou acionistas controladores em companhias com estrutura de propriedade concentrada, não carregam todo o ônus financeiro das suas decisões (BARROS; SILVEIRA, 2008, p. 514).

De acordo com Oliveira e colaboradores (2008), o conceito de governança corporativa existe há aproximadamente 60 anos. Entretanto, ela vem se transformando em uma preocupação constante em diversos países desenvolvidos e emergentes, podendo ser definida como o conjunto de mecanismos internos e externos que tem por objetivo harmonizar a relação entre os gestores e os stakeholders.

Segundo Bianchi e colaboradores (2009), o elevado crescimento das empresas levou à separação da sociedade, de forma que o comando de diversas organizações passou para terceiros, entre administradores, proprietários ou stakeholders, os quais passaram a modificar sua função, preocupando-se com a fiscalização por meio dos conselhos de administração, conselhos fiscais e auditorias externas para melhor observar o funcionamento das instituições, assim como preconizar os bons princípios de transparência.

Corroborando os autores acima, Schnorrenberger (2012) afirma que a governança 
corporativa é, sem dúvida, uma ferramenta que ajuda a subverter a assimetria das informações geradas pela cadeia de comando empresarial. No entanto, é preciso haver regras e normas bem delineadas, evoluídas com o tempo, para a sua implantação no ambiente diretivo das companhias.

Em uma comparação entres as citações utilizadas neste marco teórico referencial acerca da governança corporativa, é possível constatar que o conceito vem se reestruturando tanto no Brasil quanto no mundo afora. O cerne dos autores se situa, em especial, nas questões financeiras, cujas teses, desde 2005 (a mais antiga citada), já demonstram uma imposição da sociedade moderna, em especial na perquirição sobre transparência e ética. Também é notável o aprofundamento do conceito, em especial delineado pela motivação dos autores em apresentar a criação de boas práticas de governança frente aos epicentros de escândalos corporativos das últimas décadas e da necessidade de preservação de uma boa gestão para a longevidade das organizações. Também em uma analogia terminológica, é possível constatar que os autores reúnem argumentos direcionados aos diversos e inovadores recursos de interações e relacionamentos, que devem ser incentivados para que as gestões sejam participativas, democráticas e plurais em sua totalidade. Assim, Bianchi e colaboradores (2009) trazem uma definição ampla e completa, em especial no que concerne à fiscalização por meio de conselhos variados, visando sempre a excelência no funcionamento e perpetuando também os princípios de transparência.

Já relativamente a uma evolução entre os autores em seus conceitos, é perceptível que todos compartilham de simetria em suas definições, sendo possível a identificação de concepções que corroboram entre si e completam-se em sentidos correspondentes. Porém, é relevante destacar que os autores mais recentes (2009 e 2012) destacam a transparência das ações com a fiscalização e também a articulação das regras e normas com um bom delineamento, respaldadas pela evolução temporal.

E, por fim, é pertinente elucidar que a evolução da governança corporativa no Brasil ainda está ocorrendo (por meio de diversos fatos e por vários motivos no cenário nacional), impulsionada pelas mudanças nas estratégias empresariais, cenário econômico, social e político que perpassa por diversos setores, e também por esta análise, para o aprofundamento de boas práticas para a gestão esportiva.

\section{A Confederação Brasileira de Hóquei sobre Grama e Indoor (CBHG)}

A Confederação Brasileira de Hóquei sobre Grama e Indoor (CBHG) está localizada na cidade do Rio de Janeiro (RJ) e desde a sua fundação se mantém na mesma sede, sem ter passado por trocas de sedes entre municípios do estado do Rio de Janeiro e tampouco entre estados da Federação.

A fundação da CBHG foi estabelecida no ano de 2005 (logo após exatos quatro anos 
como Associação Brasileira de Hóquei sobre Grama), onde modificou o seu status para Confederação, por conseguinte filiada ao Comitê Olímpico Brasileiro.

Atualmente, as modalidades sob responsabilidade da CBHG são:

a) Hóquei sobre Grama: única modalidade olímpica, disputada por 11 jogadores (10 de linha e mais um goleiro) em campo sintético;

b) Hóquei Indoor: modalidade disputada em ginásios e ambientes fechados, disputada por 5 jogadores (4 de linha e mais um goleiro);

c) Hockey 5s: modalidade disputada nos Jogos da Juventude Mundial, disputada por 5 jogadores (4 de linha e mais um goleiro) em campo sintético;

d) Beach Hockey ou Hóquei sobre a areia: modalidade disputada na praia ou espaços padronizados com areia, disputada por 5 jogadores (4 de linha e mais um goleiro);

e) Hóquei Adaptado: derivações das práticas anteriores para portadores de deficiências (intelectuais e físicas).

A CBHG conta com praticantes em cinco estados da Federação (formalizados, podendo haver praticantes informais em outros estados) sendo estes: Rio Grande do Sul, Santa Catarina, Paraná, São Paulo e Rio de Janeiro, totalizando menos de mil atletas e amantes da modalidade no Brasil. Além destes cinco estados, a modalidade está se desenvolvendo no estado da Paraíba, já contando com um grupo de estudos, disciplina específica em nível superior e projetos de extensão para a expansão da modalidade na Região Nordeste do Brasil.

No que diz respeito à história da gestão da modalidade no Brasil, atualmente ela está na sua quarta gestão, sendo o atual presidente o segundo a tomar posse. Por se tratar de uma confederação relativamente jovem (14 anos de existência), uma das principais mudanças estatutárias ocorreu no ano de 2018.

A missão atual está centrada em desenvolver as práticas do Hóquei em todo o território nacional, alcançando o sucesso com as seleções nacionais, bem como o gerenciamento da modalidade no Brasil. Fazendo vista à missão proposta pela CBHG, nota-se que primordialmente o principal objetivo destacado na missão é de tornar a prática do esporte mais acessível e ampla, podendo assim alcançar outras regiões e estados do país e melhorar o trabalho através de novos projetos nos estados onde já existe a modalidade. Outro ponto destacado na missão é o de investir nos selecionados nacionais, de ambos os naipes, para que o Brasil possa se tornar uma das forças no cenário internacional, nos mais diversos campeonatos organizados pela Federação Internacional de Hóquei e também em nível olímpico. E, por fim, a responsabilidade de potencializar a gestão da modalidade está acompanhada como a importância final na missão.

Já em questão a estrutura organizacional, temos o organograma que ilustra as funções e responsabilidades presentes na CBHG, conforme apresentado na Figura 1: 


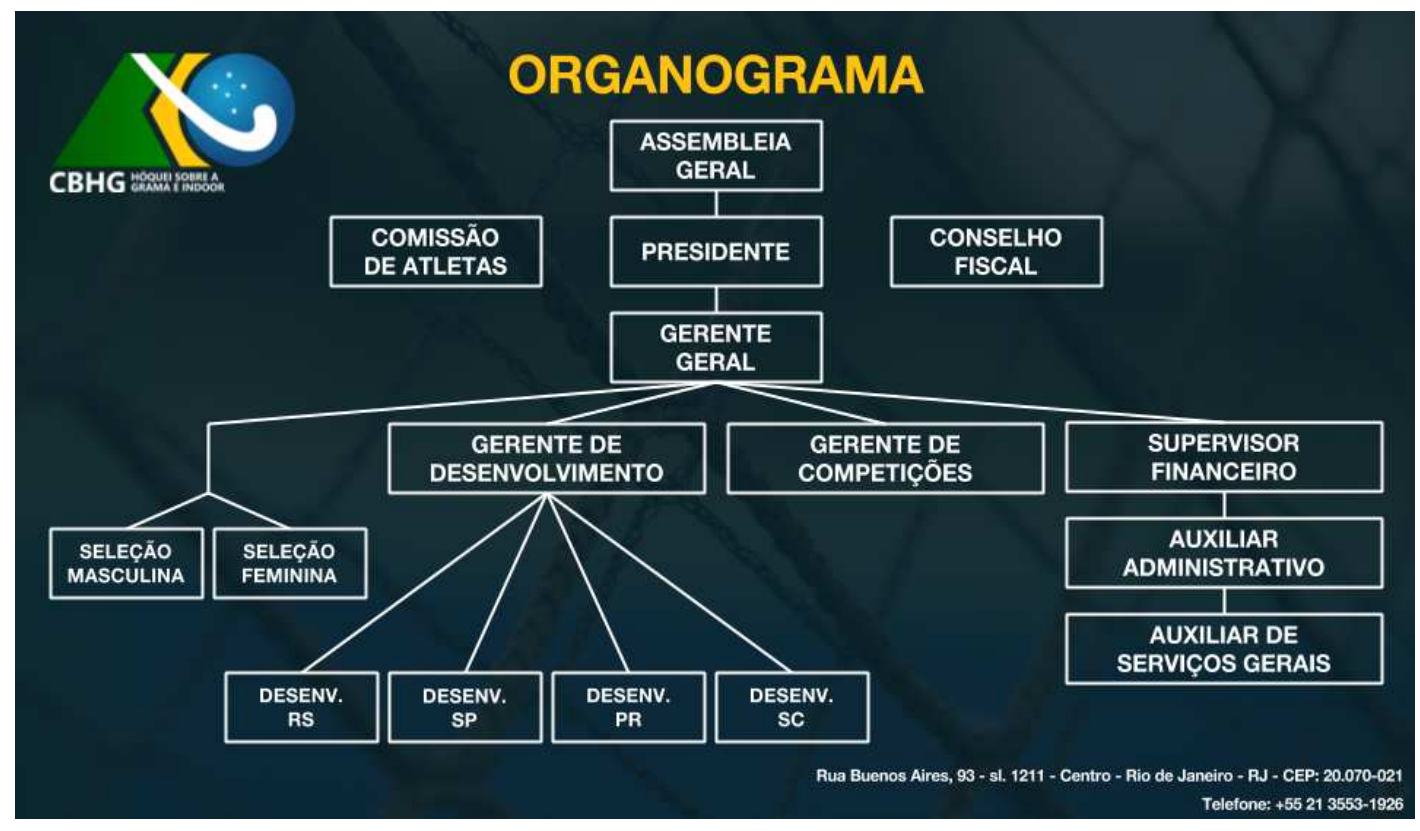

Figura 1 - organograma da CBHG.

Fonte: site da CBHG (2019).

A assembleia geral está acima no organograma por ser soberana na gestão e tratar de forma democrática a votação frente às decisões tomadas pelos seus membros. Ela é realizada nos formatos Ordinária (anual, sempre no primeiro trimestre) e Extraordinária (podendo ocorrer a qualquer momento, logo após a convocação, que é sempre executada com 30 dias de antecedência).

Logo após, temos o presidente, que é o principal gestor da entidade e que conta com a participação nas Assembleias da Comissão de Atletas e do Conselho Fiscal. Seguindo a linha hierárquica, está situado o gerente-geral, que é o gestor administrativo e esportivo da entidade e que atua diretamente com as outras gerências (desenvolvimento e de competições) e com o supervisor financeiro.

O gerente de desenvolvimento trabalha com os desenvolvedores (formadores) dos cinco estados onde existem os projetos já implementados de fomento à modalidade, o supervisor financeiro e o auxiliar administrativo.

A classificação histórica da seleção masculina para as Olimpíadas de 2016 no Rio de Janeiro foi um dos fatos mais relevantes para a modalidade, conquistada através do inédito quarto lugar nos Jogos Panamericanos de Toronto, no Canadá, no ano de 2015. Através dessa conquista, a governança da CBHG focou especialmente nas boas ações (transparência) em todo o investimento direto à seleção nacional, sempre relatando e comunicando sobre as viagens e gastos específicos para a melhor preparação para a equipe nacional. 


\section{Benefícios para a governança corporativa}

Diversos benefícios podem ser alcançados dentro da Confederação Brasileira de Hóquei sobre Grama e Indoor (CBHG) por meio da potencialização do índice de melhoria de maturidade da governança. Promover uma aproximação com as necessidades diretas dos stakeholders, aprimorar técnicas de trabalho e na gestão (novas abordagens na administração), modernizar sistemas de comunicação e informação, endereçar as modalidades esportivas para um maior número de praticantes e atentar para a distribuição de projetos inovadores para o desenvolvimento esportivo são exemplos de causa e efeito que podem ser aprimorados e analisados constantemente.

A importância que os controladores e administradores devem dar a novas atribuições e sofisticações deve estar em consonância com o enfoque do tema, que, conforme Rappaport (1998, p. 1), deve seguir a seguinte premissa: Avaliar a entidade com o intuito de gerenciá-la com base na evolução do seu valor, dando a devida preocupação para todos os setores, observando constantemente o desempenho do negócio.

Já de acordo com La Porta e colaboradores (2000, p. 23), a governança corporativa lida com as maneiras pelas quais os fornecedores de recursos garantem que obterão para si o retorno sobre seu investimento, ou seja, aqui a credibilidade é a marca registrada, quando os stakeholders podem confiar em um trabalho consciencioso das atividades estabelecidas com a OEO. Dessa forma, é possível afirmar que o ambiente deve ser favorável para os princípios de transparência e eficiência, aprimorados pelas necessidades reais dos stakeholders e as ações desenvolvidas em parceria com a CBHG. Dessa maneira, a credibilidade em diversas atividades, assim como a satisfação e confiança, será proporcionalmente aumentada e elevada com as boas ações desempenhadas pela gestão da OEO.

Outro ponto importante a salientar, com a decorrente elevação do índice de melhoria de maturidade de governança, é que se crie um ambiente favorável para a evolução de áreas administrativas até então emperradas ou inexistentes na OEO. Andrade e Rossetti (2007) conceituam que a prática da governança corporativa está principalmente estruturada na gestão de conflitos, na diminuição dos custos e no gerenciamento de relacionamentos internos e externos da corporação. Com base no exposto, retiram-se os valores da boa prática da governança corporativa, que devem preconizar especialmente os seguintes quesitos:
a) Senso de justiça, equidade;
b) Transparência;
c) Prestação responsável de contas;
d) Conformidade.

Assim, possibilita-se que as diversas áreas administrativas da OEO possam reunir uma base comum para o bom andamento de todas as características inerentes à governança corporativa. 
De acordo com Cerda (2000, p. 2), um sistema de governança corporativa possui dois objetivos essenciais:

a) Prover uma estrutura eficiente de incentivos para a administração da empresa, visando a maximização de valor;

b) Estabelecer responsabilidades e outros tipos de salva-guardas para evitar que os gestores (insiders) promovam qualquer tipo de expropriação de valor em detrimento dos acionistas (shareholders) e demais partes interessadas (stakeholders).

Analisando esses dois pontos essenciais para a governança corporativa, é admissível que, quanto mais eficaz os serviços administrativos se tornarem, melhores resultados para a boa governança serão atingidos em prol do bom funcionamento interno, que será externalizado, no caso da OEO com os stakeholders. Dessa forma, uma valorização na prestação dos serviços e atenção dedicada às constantes melhorias podem ser monitoradas pela gestão.

Com os níveis elevados para a melhoria da governança, inicia-se uma proposta de reorganização de pessoal, de estrutura e de manutenção que forjarão uma ampliação da atuação e abrangência. Com isso, tanto a OEO irá expandir o seu legado quanto os seus stakeholders encontrarão novas oportunidades para se apropriarem das melhorias.

De acordo com Bromberg (2010), o termo governança corporativa não é simples de ser trabalhado, pois este se divide em uma série de regulamentações que visam principalmente proteger os direitos, o sistema e as relações daqueles envolvidos direta ou indiretamente com o mundo corporativo. Assim, as boas práticas de governança corporativa não se resumem à manutenção dos direitos dos stakeholders, mas também envolve o relacionamento destes junto à OEO.

Com esta característica, foi possível mapear os principais stakeholders da CBHG, que diretamente podem fruir de um bom relacionamento e também dos benefícios de uma boa governança.

A promoção de um melhor relacionamento entre os administradores e os stakeholders primários e secundários pode estabelecer caminhos que tendam a uma maior valorização da OEO e melhores ambientes para a gestão corporativa e controladoria.

Conforme Bromberg (2010), esse mecanismo funciona como um sistema que visa fiscalizar se a OEO está de acordo com os estatutos legais e contratos, de modo que conduza a um gerenciamento eficaz da organização, atuando sempre com integridade, competência e responsabilidade.

A CBHG possui diversos segmentos de stakeholders, que foram detectados conforme a participação e envolvimento direto com as atividades administrativas e esportivas da entidade.

No mapeamento sobre os principais stakeholders da CBHG, podemos destacar os primários entre: 
a) Federações estaduais: filiadas à CBHG, possuem importante papel para a discussão de regulamentos, organização de eventos em nível regional e nacional, assim como participam das assembleias para deliberar sobre assuntos pertinentes à gestão da modalidade em todo o território nacional.

b) Atletas: distribuídos em diferentes categorias, também podem compor os selecionados nacionais adultos e de base.

c) Treinadores e gestores: profissionais responsáveis pela organização técnica esportiva e administrativa de clubes, federações e da própria CBHG.

d) Comitê Olímpico Brasileiro: entidade que abriga todas as modalidades olímpicas do país, em que o Hóquei sobre Grama se insere e recebe apoio administrativo e financeiro para a participação em eventos, realização de cursos e atualizações nas áreas de gestão esportiva.

e) Ministério dos Esportes: órgão de fomento para o financiamento de projetos e a manutenção da OEO.

f) Federação Pan-Americana de Hóquei sobre Grama: entidade que gere a modalidade nas américas e estabelece contato direto com a CBHG nos eventos e atividades continentais.

g) Federação Internacional de Hóquei sobre Grama: entidade que gere a modalidade no mundo e estabelece contato direto com a CBHG nos eventos e atividades internacionais em nível mundial e olímpico.

h) Clubes: filiados às federações estaduais, apresentam importante papel na gestão, votação e decisão de metas e planejamento das gestões de cada estado em que haja federações.

Já os stakeholders secundários da CBHG são:

a) Mídia: responsável pela divulgação dos eventos esportivos e também do próprio funcionamento da CBHG, divulgando diversas informações e dados acerca da administração esportiva da OEO em cenários estaduais e nacional.

b) Escolas: apesar de muitos esportes não valorizarem o potencial do esporte na escola ou da escola, percebe-se que a base da modalidade em muitos estados (principalmente em Santa Catarina e no Rio Grande do Sul) surge da capacitação de professores e também da atuação dos mesmos em equipes de base, inclusive com expressivas participações em eventos regionais e nacionais.

c) Patrocinadores: apesar de não ser uma modalidade muito popular no Brasil, a própria CBHG já conta com três patrocinadores no ano de 2017, e muitas federações em seus próprios eventos estaduais conseguem reunir a participação e apoio de patrocinadores.

d) Universidades: tanto públicas como privadas, apresentam já em diversos estados (principalmente no Rio Grande do Sul e no Rio de Janeiro) disciplinas nos currículos dos cursos 
de educação física - licenciatura e bacharelado, projetos de extensão e pesquisas atividades das modalidades de hóquei sobre grama, indoor, entre outras práticas.

e) Fãs: pessoas que acompanham as modalidades da CBHG, tanto pela mídia como junto aos mais variados eventos e competições organizados pela CBHG.

Logo após a análise da importância de todos os stakeholders primários, foram escolhidos os três mais importantes, levando-se em conta os seguintes critérios de categorização e classificação:

a) relação direta e conjunta com as atividades desenvolvidas na $\mathrm{CBHG}$;

b) trabalham diretamente em mecanismos que possam garantir a preservação de seus direitos;

c) apresentam interesse para ganhos reais de reputação da OEO, para melhorar a captação de patrocínios e investimentos.

Levando-se em conta esses requisitos que corroboram a melhoria da governança da CBHG e também para os benefícios diretos, os três stakeholders primários selecionados foram:

a) Federações estaduais: podem se respaldar nas mesmas ações sugeridas e desenvolvidas na CBHG (concernentes à boa governança) para a sua própria gestão; podem melhorar a sua imagem conjuntamente frente aos clubes e seus atletas, desenvolver projetos conjuntos de transparência e boa gestão e compartilhar atividades, patrocinadores e investimentos.

b) atletas: estes podem se beneficiar de uma boa organização para ver suas modalidades crescendo, desenvolver trabalhos e oportunidades em conjunto com a OEO, compor comissão de atletas, respeitando os princípios de igualdade (gênero e inclusão);

c) treinadores/gestores da modalidade: possibilidade de cooperação de boas ações (palestras, oficinas, cursos) e compartilhamento de ideias para a gestão e atuação esportiva profissional na CBHG.

\section{Metodologia}

Esta pesquisa teve como delineamento a característica qualitativa, descritiva, transversal e exploratória acerca do nível de governança da CBHG. Como instrumentos para coleta de dados, a análise documental foi inicialmente utilizada para que fossem levantados conteúdos de relevância para a realização desta pesquisa, junto à técnica de entrevista semiestruturada envolvendo o dirigente da OEO.

Mensurar as condições de maturidade de uma organização, instituição ou órgão não é uma tarefa tão simples. Primeiramente, a depender da organização, questões históricas, hierárquicas, culturais e políticas podem ser grandes empecilhos para pesquisadores ou avaliadores atuarem para que possam coletar informações precisas para qualquer tipo de 
avaliação. Muitas vezes, essa falta de flexibilidade por parte dos dirigentes e gerentes das diversas áreas da instituição podem delimitar informações que podem ser muito valiosas e pertinentes para a análise e validade do grau de maturidade da governança, o que pode resultar em um levantamento de dados incoerentes com a situação em que tal entidade pode realmente se encontrar.

Desta forma, todos os envolvidos em determinados levantamentos sobre a realidade da organização devem passar por esclarecimentos, palestras, reuniões, oficinas e workshops para que uma melhor compreensão e entendimento das ferramentas e instrumentos da coleta de dados possam ser apresentados e que, através dessas dinâmicas, as dúvidas, inquietações e resistências possam ser trabalhadas e sanadas para que o processo posterior, ou seja, da coleta das informações, possa ocorrer com o maior grau de credibilidade e transparência.

Assim sendo, resistências quanto à abertura de esclarecimentos podem ser minimizadas e a coleta pode desta forma ocorrer com uma condução fidedigna, sem que dirigentes e administradores omitam ou se sintam incomodados em disponibilizar informações pertinentes para o levantamento dos dados.

Isso se deve, como por exemplo, em organizações que estão há muito tempo com os mesmos dirigentes no poder, estando suas ações de governança correndo o risco de ser compreendidas como "fragilizadas" quando alguém ou uma iniciativa possa vir a contestar a falta de administração ou incoerência em determinadas áreas. Desta maneira, fornecer dados e informações detalhados para determinada coleta ou instrumento de pesquisa pode se tornar um verdadeiro desafio para que se possa realmente trabalhar e coletar com precisão. Muitas vezes, em contrapartida, podemos observar que, mesmo estando há muitos anos à frente da gestão de organizações, muitos reconhecem que determinadas iniciativas podem trazer melhorias para as entidades, assim como atualizações, inovações e apontamentos para melhorias na gestão da organização. Para tanto, o procedimento de coleta de informações para mensurar o grau de maturidade, antes de ser iniciado, deve trazer clareza sobre os benefícios que posteriormente serão aplicados ou sugeridos para a entidade.

Seguindo esses princípios, o avaliador ou grupo que irá coletar os dados, certamente, antes de iniciar qualquer iniciativa, deve ter clareza da metodologia. Assim, uma atribuição de um projeto piloto para testagem dos passos e etapas se torna pertinente e importante para que a coleta ocorra de forma serena e sem percalços durante o percurso, contribuindo para que todo o processo avaliativo não passe por resistências e problemáticas que possam comprometer o andamento das coletas e também da veracidade e fidedignidade dos dados.

Para isso, devem-se elucidar claramente as etapas, dentro de um planejamento que possa principalmente elencar os seguintes momentos:

a) levantamento de dados da organização (dados gerais e necessidades a serem avaliadas); 
b) escolha da ferramenta para atribuir o melhor grau de maturidade de governança da organização;

c) realização de um projeto piloto para testagem do instrumento (podendo ser realizado em uma outra organização ou com profissionais da área para a validação do instrumento);

d) planejamento do cronograma das atividades de coleta de dados (agendamentos, averiguação de disponibilidade, espaços, materiais para entrevista, questionários, enquetes etc);

e) dinâmicas para esclarecimentos, palestras, reuniões, oficinas e workshops para uma melhor compreensão e entendimento das ferramentas e instrumentos da coleta de dados;

f) realização da coleta de dados;

g) análise dos dados;

h) apresentação e intervenção para a melhoria do grau de maturidade de governança.

Todas as etapas devem seguir rigorosamente uma distribuição de prazos de realização, para que o processo todo tenha total sucesso e não ocorram atrasos dentro do cronograma planejado previamente. Assim, o processo terá fluidez e demonstrará uma estruturação adequada para sua execução posterior dentro da entidade, promovendo dessa forma uma boa organização para auxiliar na mensuração do grau de maturidade da governança.

Na Organização Esportiva Olímpica (OEO) - Confederação Brasileira de Hóquei sobre Grama e Indoor (CBHG), o levantamento de dados para a mensuração do grau de maturidade utilizou a ferramenta do questionário online GET, estruturado pela equipe de TI do Comitê Olímpico Brasileiro (COB).

Esse instrumento consiste no preenchimento de questionamentos acerca de diversos itens que na plataforma apresentavam as opções das respostas em: a) Sim; b) Não; e em conjunto, como complementação, o upload de documentos digitalizados no formato online (estatuto, resoluções, atas etc.) como comprovação às respostas. Os questionamentos versavam em blocos de 1 a 5 (onde os questionamentos se agrupavam em uma classificação de grau mais simples até o mais complexo). Os seguintes tópicos foram estruturados para que os questionamentos ocorressem:
a) Estatuto e Contrato Social;
b) Assembleia Geral;
c) Comitê de Auditoria;
d) Conselho de Administração;
e) Conselho Fiscal;
f) Diretoria; 
g) Estrutura Organizacional, Papéis e Responsabilidades;

h) Processo Eleitoral.

Após o completo preenchimento, o escore é apontado em todas estas áreas supracitadas, onde o ranking de 1 (mais baixo) a 5 (mais elevado) demonstra o grau de maturidade de governança nos determinados tópicos.

Os passos práticos para a mensuração do grau de maturidade da Confederação Brasileira de Hóquei sobre Grama e Indoor (CBHG) ocorreram durante o período de 45 dias, em que diversas etapas foram elaboradas para minimizar o impacto dentro da OEO.

Dentre os itens apresentados anteriormente, sobre o item "a" - levantamento da organização (dados gerais e necessidades), o próprio questionário do GET já veio estruturado com as áreas para coleta, porém, os documentos para análise documental foram investigados e todos elencados para posterior consulta e complementação no formulário online.

$\mathrm{O}$ item "b" - escolha da ferramenta para atribuir o melhor grau de maturidade de governança da organização, não foi necessário, por este item ser contemplado pela sugestão do Comitê Olímpico Brasileiro (COB). A realização de um projeto piloto para testagem do instrumento, constituído pelo item "c" foi feito na realidade como um treinamento pelo próprio investigador, para avaliar a ferramenta, e não especificamente em uma outra entidade. Isso serviu para que ele tivesse um prévio conhecimento para poder ter um melhor domínio da ferramenta no momento da coleta.

O item "d" - planejamento do cronograma das atividades de coleta de dados, foi estruturado para que dois agendamentos de entrevista com o presidente da Confederação Brasileira de Hóquei sobre Grama e Indoor (CBHG) ocorressem durante duas semanas. Estas entrevistas aconteceram por videoconferência, em se tratando da distância geográfica entre o pesquisador e a sede da CBHG.

O item "e" - dinâmicas para esclarecimentos, palestras, reuniões, oficinas e workshops para uma melhor compreensão e entendimento das ferramentas e instrumentos da coleta de dados, não ocorreu de forma efetiva, pois por se tratar de uma entidade jovem e também com um dirigente que recentemente tomou posse de seu mandato, o investigador organizou os devidos esclarecimentos sobre a coleta de dados para que nenhum constrangimento ocorresse durante o processo.

Os itens "f", "g" e "h", envolvendo a realização da coleta de dados, análise dos dados e apresentação e intervenção para a melhoria do grau de maturidade de governança, ocorreram no período de duas semanas.

Para a realização da coleta de dados, o principal desafio foi a localização nos documentos da OEO dos dados para este estudo. Durante as entrevistas, o presidente auxiliou prontamente com diversos itens e também atuou na procura nos documentos das comprovações dos quesitos existentes e não existentes. Porém, no momento da entrevista, a 
espontaneidade e auxílio do entrevistado foram marcas positivas para que um bom preenchimento ocorresse, de forma efetiva e completa.

\section{Apresentação dos resultados}

Logo após o período de 45 dias de coleta de dados, a análise foi realizada na base do sistema GET, onde foi calculado e sugerido o grau de maturidade nas diferentes áreas da entidade. Com isso, foi possível constatar, conforme os dados no Quadro 1, os seguintes resultados:

Quadro 1 - pontuação atingida pela CBHG.

\begin{tabular}{|l|l|}
\hline Tema & Nota da OE \\
\hline Estatuto e Contrato Social & 1 \\
\hline Assembleia Geral & 1 \\
\hline Comitê de Auditoria & 2 \\
\hline Conselho de Administração & 1 \\
\hline Conselho Fiscal & 1 \\
\hline Diretoria & 1 \\
\hline Estrutura Organizacional, Papéis e responsabilidades & 1 \\
\hline Processo Eleitoral & 1 \\
\hline
\end{tabular}

Fonte: relatório final da pesquisa (2018).

O quadro acima apresenta a pontuação, sendo que os itens diretoria, estrutura organizacional, papéis e responsabilidade e processo eleitoral não obtiveram pontuação. Por sua vez, o conselho fiscal, conselho de administração, assembleia geral, estatuto e contrato social ficaram com pontuação 1, e somente o comitê de auditoria com a pontuação mais elevada entre todas, com 2 pontos (sendo que o máximo possível de ser atingido é o de valor 5).

Através desses dados, uma análise prioritária foi realizada para o relatório final e seleção de três áreas (dentre as oito) para que o projeto de melhoria do índice de maturidade fosse colocado em prática.

Os três temas escolhidos para os projetos de implementação / melhoria foram:

a) Estatuto e Contrato Social;

b) Assembleia Geral;

c) Estrutura Organizacional, papéis e responsabilidade.

A seleção desses itens para a análise de implementação se deu pela relevância de 
poderem atingir a pontuação 5 , pois eles se destacam como os pilares da organização e devem consequentemente apresentar melhorias.

Para que melhorias sejam efetuadas em qualquer OEO, torna-se imprescindível que um bom projeto seja organizado e estruturado para a sua devida implementação. No caso da CBHG, a melhoria do índice de maturidade é o objetivo principal para que a entidade possa gozar de uma evolução estrutural em sua gestão e que possa compartilhar com seus stakeholders excelentes níveis de boa governança.

Para isso, a seleção dos três temas de governança a) Estatuto; b) Assembleia Geral; c) Estrutura Organizacional, Papéis e Responsabilidade sustentam inicialmente a melhoria para que futuros temas possam também ser observados e planejados para atingir melhorias dentro da entidade. Estes três temas selecionados em questão trarão à Organização Esportiva Olímpica (OEO) uma estruturação na base, pois o estatuto é o princípio das ações da gestão e o regulamento para todas as atividades desempenhadas. Juntamente, a Assembleia Geral possui o poder executivo da entidade e detém soberania sobre todas as decisões a serem tomadas acerca da gestão do esporte em território nacional. E, por fim, a Estrutura Organizacional, Papéis e Responsabilidade demonstram o bom funcionamento, destacando as funções e atribuições a serem seguidos e desempenhados para a boa gestão e transparência da entidade.

O Estatuto se torna o principal mecanismo para a manutenção de uma boa gestão e também para o bom funcionamento de qualquer OEO. Através desse documento formalizado, a administração se torna bem estruturada e amplia as diversas ações para diversas frentes.

De acordo com o IBGC (2018), o estatuto deve estabelecer o objetivo social da organização, sua denominação, os direitos e deveres dos associados, a representação da organização e dispor sobre a assembleia geral e administradores, entre outros tópicos.

O estatuto social existe para ser conhecido, assim como suas devidas alterações devem ser constantemente estimuladas através de discussões e apreciação das partes e composição, pois o conhecimento e o cumprimento do seu conteúdo devem ser do interesse de todos os gestores, assim como dos respectivos stakeholders.

Um dos órgãos integrantes de uma OEO é a assembleia geral, cuja função é deliberativa. É por meio desse órgão que os filiados podem deliberar sobre assuntos de elevada importância para a entidade. Portanto, para que ele exerça sua função deliberativa, torna-se necessário que os associados reunam-se e votem sobre os assuntos apresentados nas assembleias gerais (POMPEU, 2014, p. 73).

A assembleia geral é classificada como ordinária (AGO) ou extraordinária (AGE), sendo que essas devem sempre ocorrer com uma pauta preestabelecida e enviada com antecedência mínima para que inclusões sejam feitas ou questionadas em cada um dos encontros deliberativos.

A assembleia geral ordinária é sempre estruturada anualmente (no início do ano, no 
primeiro trimestre), para principalmente realizar a prestação e aprovação das contas e também tratar de eleições, para que as chapas dos grupos gestores sejam apreciadas e votadas. Já a assembleia geral extraordinária pode acontecer a qualquer momento do ano com a convocação e pautas específicas dos assuntos que serão abordados.

De acordo com o IBGC (2018) a Assembleia Geral é o foro para manifestação dos associados e para prestação de contas. As assembleias têm como competência a eleição e destituição dos membros do conselho de administração, a destituição dos membros da diretoria, a aprovação das contas, a alteração do estatuto social, a deliberação do orçamento e outras decisões do interesse do instituto, conforme seu estatuto social. Assim, todos os associados, desde que em situação regular de suas obrigações financeiras e associativas perante a OEO, têm direito a voto em decisões da entidade e nas eleições.

A respeito da Estrutura Organizacional, Papéis e Responsabilidade, pode-se destacar que este tema é o centro da atuação dos gestores de cada OEO e deve apresentar normatizações específicas, assim como coerência nas atribuições a serem desempenhadas nas entidades.

Conforme Araújo (2007), a estruturação organizacional é uma forma sistematizada de agrupar diversas atividades em frações organizacionais definidas, percorrendo um determinado critério, objetivando assim a melhor adequação da estrutura organizacional e sua própria dinâmica de ação. Ainda conforme o autor, os objetivos da estruturação podem ser definidos nos seguintes critérios:

a) aproveitar a especialização: para poder tirar o máximo da qualificação das pessoas, aumentando a eficiência funcional, em benefício da própria organização;

b) maximizar os recursos disponíveis: a estruturação de unidades obedece aos vários recursos existentes; a maximização desses recursos ocorre no momento do agrupamento das atividades da organização;

c) controlar: na estruturação, as responsabilidades devem estar claramente delimitadas para um adequado processo de controles e mensuração de resultados;

d) coordenar: quanto maior for o grau de coordenação em uma organização, mais serão integrados os esforços individuais;

e) descentralizar: a descentralização resulta de procedimentos relacionados à delegação da responsabilidade e da autoridade;

f) integrar ambiente e organização: a estruturação organizacional deve ser planejada e executada levando-se em conta as perspectivas internas e os fatores externos.

Dessa forma, para a OEO é de suma importância que esses aspectos possam ser respeitados e seguidos para uma boa manutenção de papéis a serem desempenhados, assim como a responsabilidade nas atribuições que são destinadas para os gestores e também para os colaboradores que compõem as OEO.

Para que todos esses três temas possam seguir as preconizações da literatura consultada, 
assim como destacar os resultados obtidos através da ferramenta GET, os resultados deste estudo apontam necessidades de organização dos parâmetros dos níveis iniciais ao nível almejado, com a estruturação de uma meta acompanhada de uma ação para a intervenção junto à CBHG.

Dentre as metas do Quadro 2, apresenta-se o nível pretendido para se alcançar (inicialmente 3, passando pelo 4 até o nível 5) com relação ao Estatuto:

Quadro 2 - metas pretendidas perante o Estatuto.

\begin{tabular}{|c|c|c|c|}
\hline $\begin{array}{c}\text { NÍVEL A } \\
\text { ALCANÇAR }\end{array}$ & ITEM & METAS & AÇÃO \\
\hline 3 & $\begin{array}{c}\text { Criação de uma Comissão } \\
\text { de Atletas e Ex-Atletas para } \\
\text { a promoção do } \\
\text { desenvolvimento da } \\
\text { modalidade. }\end{array}$ & $\begin{array}{l}\text { Realizar a } \\
\text { alteração no } \\
\text { estatuto. }\end{array}$ & $\begin{array}{c}\text { Convite aos atletas e } \\
\text { ex-atletas e reunião } \\
\text { para a formação da } \\
\text { Comissão e deliberar } \\
\text { sobre o assunto. }\end{array}$ \\
\hline 4 & $\begin{array}{l}\text { Proibição de concessão de } \\
\text { empréstimos e garantias em } \\
\text { favor do controlador e } \\
\text { demais administradores. }\end{array}$ & $\begin{array}{l}\text { Realizar a } \\
\text { alteração no } \\
\text { estatuto. }\end{array}$ & $\begin{array}{l}\text { Organização do } \\
\text { código de conduta da } \\
\text { CBHG } \\
\text { (implementação do } \\
\text { EC Finanças). } \\
\end{array}$ \\
\hline 5 & $\begin{array}{l}\text { O Estatuto adota política de } \\
\text { igualdade, diversidade e } \\
\text { inclusão para mulheres na } \\
\text { composição de seus } \\
\text { colegiados deliberativos. }\end{array}$ & $\begin{array}{l}\text { Realizar a } \\
\text { alteração no } \\
\text { estatuto. }\end{array}$ & $\begin{array}{l}\text { Reunião atletas, ex- } \\
\text { atletas e comissões } \\
\text { técnicas do naipe } \\
\text { feminino para } \\
\text { assumirem } \\
\text { futuramente cargos. }\end{array}$ \\
\hline 5 & $\begin{array}{l}\text { As revisões do Estatuto } \\
\text { levam em conta as } \\
\text { sugestões do público } \\
\text { interessado, que pode } \\
\text { comunicar-se com a } \\
\text { entidade a partir de um } \\
\text { canal específico. }\end{array}$ & $\begin{array}{l}\text { Realizar a } \\
\text { alteração no } \\
\text { estatuto. }\end{array}$ & $\begin{array}{l}\text { Disponibilizar no } \\
\text { site institucional um } \\
\text { espaço para } \\
\text { sugestões do público } \\
\text { interessado. }\end{array}$ \\
\hline
\end{tabular}

Fonte: Relatório da pesquisa (2018).

As ações apresentadas foram estruturadas em consonância com as metas, sempre tendo em vista a melhoria a ser atingida gradativamente perante o nível a ser alcançado no grau de maturidade do item.

O Quadro 3 apresenta o nível pretendido para se alcançar (inicialmente 2, passando pelo 3 e 4 até o nível 5) com relação à Assembleia Geral: 
Quadro 3 - metas pretendidas perante a Assembleia Geral.

\begin{tabular}{|c|c|c|c|}
\hline NÍVEL & ITEM & METAS & AÇÃO \\
\hline 2 & $\begin{array}{l}\text { Principais regras de } \\
\text { funcionamento da AGO e } \\
\text { AGE - convocações, } \\
\text { atribuições, composição, } \\
\text { documentação. }\end{array}$ & $\begin{array}{l}\text { Normatizar as principais } \\
\text { regras (regulamento). }\end{array}$ & $\begin{array}{c}\text { Reunião com a Presidência e } \\
\text { o Gerente Geral para redação } \\
\text { e organização das regras } \\
\text { (regulamento). }\end{array}$ \\
\hline 3 & $\begin{array}{c}\text { Convocações com } \\
\text { antecedência mínima de } 30 \\
\text { dias. }\end{array}$ & Normatizar a convocação. & $\begin{array}{l}\text { Institucionalizar a norma } \\
\text { para todas as AG. }\end{array}$ \\
\hline 4 & $\begin{array}{c}\text { Estabelecer na AG orçamento } \\
\text { total anual da remuneração } \\
\text { dos membros dos poderes da } \\
\text { entidade. }\end{array}$ & $\begin{array}{l}\text { Normatizar as principais } \\
\text { regras (regulamento). }\end{array}$ & $\begin{array}{c}\text { Reunião com a Presidência e } \\
\text { o Gerente Geral para redação } \\
\text { e organização das regras } \\
\text { (regulamento). }\end{array}$ \\
\hline 5 & $\begin{array}{c}\text { A AG aprova o orçamento } \\
\text { total anual da remuneração } \\
\text { dos membros dos poderes da } \\
\text { entidade. }\end{array}$ & $\begin{array}{c}\text { Realizar a alteração no } \\
\text { estatuto. }\end{array}$ & Apresentação na AG. \\
\hline
\end{tabular}

Fonte: Relatório da pesquisa (2018).

A respeito das alterações na Assembleia Geral, na própria Assembleia Geral Ordinária de 2019 já foram instituídas modificações que foram deliberadas, assim como o tratamento das convocações para se atingir o nível máximo de 5.

Já o quadro 4 apresenta o nível pretendido para se alcançar (inicialmente 2, passando pelo 3 e 4 até o nível 5) com relação à Estrutura Organizacional, Papéis e Responsabilidade:

Quadro 4 - metas pretendidas perante a Estrutura Organizacional, Papéis e 
Responsabilidade.

\begin{tabular}{|c|c|c|c|}
\hline NÍVEL & ITEM & META & AÇÃO \\
\hline 2 & $\begin{array}{l}\text { Definir e formalizar os principais } \\
\text { papéis e responsabilidades de cada } \\
\text { função. }\end{array}$ & $\begin{array}{l}\text { Estruturação do RH } \\
\text { para as funções. }\end{array}$ & \begin{tabular}{|c|} 
Reunião com a \\
Presidência e \\
Gerência. \\
Reuniões com o Staff \\
para sugestões e \\
deliberação da \\
formalização. \\
\end{tabular} \\
\hline 3 & $\begin{array}{l}\text { Customizar o sistema de informação } \\
\text { que suporta os processos da entidade. }\end{array}$ & $\begin{array}{l}\text { Apresentar um Canal } \\
\text { de transparência no } \\
\text { site institucional }\end{array}$ & $\begin{array}{l}\text { Estruturação, no site } \\
\text { institucional, de } \\
\text { relatórios trimestrais. }\end{array}$ \\
\hline 4 & $\begin{array}{l}\text { Estabelecer que o controle da } \\
\text { conformidade das tomadas de decisão } \\
\text { seja de responsabilidade da área de } \\
\text { controles internos. }\end{array}$ & $\begin{array}{l}\text { Realizar a alteração no } \\
\text { estatuto e formalizar } \\
\text { os principais } \\
\text { stakeholders. }\end{array}$ & $\begin{array}{c}\text { Reunião com a } \\
\text { Presidência e } \\
\text { deliberação para } \\
\text { mudança estatutária. }\end{array}$ \\
\hline 5 & $\begin{array}{c}\text { Disponibilizar um canal de } \\
\text { comunicação e um procedimento para } \\
\text { recebimento de contribuições das } \\
\text { melhorias. }\end{array}$ & $\begin{array}{l}\text { Apresentar um Canal } \\
\text { de transparência no } \\
\text { site institucional }\end{array}$ & \begin{tabular}{|} 
Disponibilizar no site \\
institucional um \\
espaço para sugestões \\
do público \\
interessado. \\
Reuniões bimestrais \\
para análise das \\
contribuições.
\end{tabular} \\
\hline
\end{tabular}

Fonte: Relatório da pesquisa (2018).

No que concerne às metas referentes às melhorias da Estrutura Organizacional, Papéis e Responsabilidade, o quadro acima apresenta características pontuais quanto à prestação de serviços da OEO, assim como ações que trazem propósitos para serem implementados no decorrer do ano de 2019. Estas ações irão ao encontro da elevação do nível, para que a CBHG possa manter a melhor estruturação organizacional possível e que possa constantemente discutir e aprovar progressos nessa referida área.

Seguindo uma organização para uma estrutura analítica de projetos (EAP), conforme o modelo de Xavier (2009), a seguinte organização foi estruturada para a implementação de ações para as melhorias do índice de governança através da seguinte forma:

a) Definição do projeto: melhoria do índice de maturidade da CBHG: apreciação do projeto completo, contendo as suas etapas, cronograma, metas e ações.

b) Organização dos objetivos: especificar dentro do projeto o que cada objetivo almeja para que o nível do rating seja contemplado e aprimorado dentro das ações propostas. 
c) Ações para o estatuto: conforme já apresentado no Quadro 2, estas ações serão sequenciais e desencadearão diversas etapas para que todos os objetivos propostos sejam alcançados. Os pontos seguintes serão incluídos no cronograma de execução para as devidas melhorias para o estatuto:

d) Criar uma comissão de atletas e ex-atletas para a promoção do desenvolvimento da modalidade.

e) Normatizar a proibição de concessão de empréstimos e garantias em favor do controlador e demais administradores.

f) Prever no estatuto adoção de política de igualdade, diversidade e inclusão para mulheres na composição de seus colegiados deliberativos.

g) Desenvolver um canal específico para que o público interessado possa enviar as sugestões acerca do estatuto.

h) Ações para a assembleia geral: conforme já apresentado no Quadro 3, estas ações serão sequenciais e desencadearão diversas etapas para que todos os objetivos propostos sejam alcançados. Os pontos seguintes serão incluídos no cronograma de execução para as devidas melhorias para a assembleia geral:

i) Estruturar as principais regras de funcionamento da AGO e AGE - convocações, atribuições, composição, documentação.

j) Normatizar o envio das convocações com antecedência mínima de 30 dias.

k) Apresentar nas AG o orçamento total anual da remuneração dos membros dos poderes da entidade.

1) Normatizar que nas AG seja aprovado o orçamento total anual da remuneração dos membros dos poderes da entidade.

m) Ações para a Estrutura Organizacional, Papéis e Responsabilidades: conforme já apresentado no Quadro 4, estas ações serão sequenciais e desencadearão diversas etapas para que todos os objetivos propostos sejam alcançados. Os pontos seguintes serão atribuídos no cronograma de execução para as devidas melhorias para a Estrutura Organizacional, Papéis e Responsabilidades:

n) Definir e formalizar os principais papéis e responsabilidades de cada função dentro da CBHG.

o) Customizar o sistema de informação que possa suportar os processos da entidade.

p) Estabelecer que o controle da conformidade das tomadas de decisão seja de responsabilidade da área de controles internos.

q) Disponibilizar um canal de comunicação e um procedimento para recebimento de contribuições de melhorias.

Assim sendo, esta organização de estrutura analítica de projetos contemplou a execução do pacote de trabalho para acompanhar e efetivar as mudanças pertinentes a cada item de 
melhoria de índice de maturidade da entidade. Essa concretização já se esboça como um importante legado para as futuras gestões esportivas da $\mathrm{CBHG}$, em especial pelo respaldo que deve ser adotado para legitimação coletiva (deliberação em assembleia geral) dessas mudanças, para que e OEO possa desfrutar de um padrão elevado de governança corporativa e para que essa mudança fique registrada na história da gestão da entidade como um exemplo a ser seguido e sempre aprimorado.

\section{Conclusão}

A boa governança dentro de um organização esportiva olímpica é um ponto crucial para o sucesso da administração e boa utilização dos recursos para que a modalidade possa tanto se desenvolver em nível nacional como se manter com bons resultados. Para tanto, um grande empenho por parte dos grupos gestores se faz necessário para que diversos problemas encontrem soluções, para que oportunidades se tornem concretizações, para que falhas possam ser sanadas.

Frente a diversos quesitos que devem ser constantemente analisados e discutidos, neste estudo entraram o estatuto, a assembleia geral e a estrutura organizacional. Estes três temas constituem a base para que a OEO possa gozar de boa atuação, sobre a qual diretamente o estatuto apresentará o funcionamento, suas regras, deveres, sendo o conteúdo que rege a administração da modalidade em território nacional. Seria o aporte que deve estar sempre condizente com as boas ações em prol do esporte e de seus stakeholders. Já a atualização da assembleia geral, órgão deliberativo mais importante de qualquer OEO, também deve apresentar uma boa regulamentação para a interação com os associados e para prestação de contas. E, por fim, a estrutura organizacional é a composição vital para que a OEO possa ter uma atuação plena em sua funcionalidade e competências a serem atribuídas na gestão em todas as áreas. Desta forma, torna-se fundamental uma reestruturação para que a OEO possa usufruir de um bom funcionamento.

Um bom caminho para implementar as melhorias para a organização esportiva olímpica, também, é buscar se espelhar em boas ações de governança de outras entidades, tanto em nível nacional como internacional (independentemente de ser a mesma modalidade), pois através de bons exemplos se pode analisar o cenário de outrora e as contribuições que foram realizadas para determinada entidade. Com isso, essa percepção de resolução de um fato isolado, ou até mesmo da governança como um todo, é fundamental dentro de uma organização esportiva olímpica e deve ser constantemente discutida pelos gestores. Através dessa conscientização, diversas ações podem se modernizar, atualizar e oferecer uma nova atmosfera para a administração, contribuindo diretamente para o sucesso de projetos que tragam melhorias diretas para o esporte.

O esporte olímpico brasileiro poderá conquistar grandes avanços e conquistas se o seu 
pilar principal, ou seja, a gestão do desporto, estiver afinado com a determinação, transparência e competência. Porém, essas características fundamentais para a adequação de uma boa gestão exigem total perseverança e investimento, em especial do seu quadro de colaboradores, que devem ser estimulados com o suporte e apoio da gestão de pessoas, para que sejam realizados treinamentos, atualizações e cursos específicos para a atuação nas mais variadas áreas da OEO. Esse incentivo, apesar de ser visto por alguns como custoso ou inapropriado, deve ser encarado como um recurso fundamental para motivação dos colaboradores e abertura de novas experiências laborais que contribuirão diretamente para o bom funcionamento e gestão da entidade. Assim, a OEO poderá estar atualizada com novos conceitos de gestão e manter um ambiente ativo, dinâmico e com boas relações interpessoais para as tomadas de decisões. Essa é uma das premissas da gestão corporativa, que pode ser amplamente correspondida para a evolução de novas ações.

Corroborando com essa proposta, também é viável uma constante coleta de retroalimentação por parte dos colaboradores sobre todos os setores, além da observação das falhas e dos componentes que precisam ser melhorados e atualizados. Como uma engrenagem, todas as áreas da gestão (marketing, finanças, esportiva-técnica, administrativa) perceberão que mudanças são sempre necessárias e pertinentes para a evolução de qualquer organização. Esse fortalecimento, boa comunicação e participação trarão excelentes avanços para a união, favorecendo um trabalho conjunto e coeso para alavancar a OEO.

Dentro dessa perspectiva, uma maior credibilidade dos stakeholders se elevará, tanto nas relações já estabelecidas quanto em futuras ações conjuntas. Assim, ao apresentar essas melhorias para implementação na Confederação Brasileira de Hóquei sobre Grama e Indoor (CBHG), que, mesmo se tratando de uma entidade relativamente jovem em nosso território nacional, busca primar por princípios da governança corporativa, para que todas as áreas de desenvolvimento de uma gestão sejam potencializadas e cada vez mais qualificadas.

Para novos desdobramentos é recomendado, através da finalização deste estudo, que a governança corporativa seja analisada em outras entidades esportivas a fim de manter níveis de igualdade na gestão esportiva nacional e que exemplos de boa governança possam ser avaliados e compartilhados em comunicações científicas.

\section{Referências}

ANDRADE, Adriana; ROSSETTI, José Paschoal. Governança Corporativa. Fundamentos, Desenvolvimento e Tendências. 3. ed. São Paulo: Editora Atlas, 2007.

ARAÚJO, Luis César. Organização, sistemas e métodos e as tecnologias de gestão organizacional: arquitetura organizacional, benchmarking, empowerment, gestão pela qualidade total, reengenharia. 3. ed. São Paulo: Atlas, 2007.

BARROS, Lucas Ayres; SILVEIRA, Alexandre. Determinantes da Qualidade da Governança Corporativa das Companhias Abertas Brasileiras. Revista Eletrônica de Administração, v. 14, 
n. 3, 2008.

BIANCHI, Márcia; SILVA, Carolina Vianna; GELATTI, Rosemary; ROCHA, João Marcos Leão. A evolução e o perfil da governança corporativa no Brasil: um levantamento da produção científica do ENANPAD entre 1999 - 2008. Encontro Anual da ANPAD (33.: 2009 set.: São Paulo). [Anais do EnANPAD]. São Paulo: ANPAD, 2009. Disponível em: <http://seer.ufrgs.br/ConTexto/article/view/11329/6702>. Acesso em: 12 set. 2018.

BROMBERG, Bruno Ouriques. Conceituação, Evolução e Benefícios da Governança Corporativa no Âmbito Empresarial: Estudo do Desempenho da Empresa Gaúcha Renner S.A. 2010. 27 f. Trabalho de Conclusão de Curso em Ciências Econômicas - Faculdade de Ciências Econômicas, Universidade Federal do Rio Grande do Sul, Porto Alegre, 2010.

CERDA, Álvaro Clark. Tender Offers, Takeovers and Corporate Governance. The Latin America Corporate Governance Roundtable, São Paulo, abril, 2000.

GRÜN, Roberto. Convergência das Elites e Inovações Financeiras: a governança corporativa no Brasil. Revista Brasileira de Ciências Sociais, v. 20, n. 58, UAEM, 2005.

INSTITUTO BRASILEIRO DE GOVERNANÇA CORPORATIVA (IBGC). Governança Corporativa. Disponível em: $<$ https://www.ibgc.org.br/conhecimento/governancacorporativa >. Acesso em: 10 set. 2018.

- Assembleia Geral. Disponível

em:<http://www.ibgc.org.br/index.php/ibgc/governanca-do-ibgc/assembleia-geral $>$. Acesso em: 17 jan. 2019.

MARQUES, Maria da Conceição da Costa. Aplicação dos princípios da governança corporativa ao setor público. Revista de Administração Contemporânea, v. 11, n. 2, Curitiba, abr./jun. 2007.

OLIVEIRA, Alexandre Martins Silva; FARIA, Anderson de Oliveira; OLIVEIRA, Luiz Martins; ALVES, Paulo Sávio Lopes da Gama. Contabilidade internacional: gestão de riscos, governança corporativa e contabilização de derivativos. São Paulo: Atlas, 2008.

POMPEU, Ivan Guimarães. Assembleia Geral de Credores. São Paulo: Ed. Dplacido, 2014.

RAPPAPORT, Alfred. Creating Shareholder Value; A Guide for Managers and Investors. 2. ed. Nova Iorque: The Free Press, 1998.

SCHNORRENBERGER, Alan Paveck. A Evolução da Governança Corporativa no Brasil. 2012. 27 f. Trabalho de Conclusão de Curso em Ciências Contábeis - Faculdade de Ciências Econômicas - Universidade Federal do Rio Grande do Sul, Porto Alegre, 2012.

LA PORTA, Rafael; LOPEZ-DE-SILANES, Florencio; SHLEIFER, Andrei; VISHNY, Robert. Investor Protection and Corporate Governance. Journal of Financial Economics. v. 58, n. 1-2, 2000.

XAVIER, Carlos Magno da Silva. Gerenciamento de Projetos: Como definir e controlar o escopo do projeto. 2. ed. São Paulo: Saraiva, 2009.

Artigo recebido em: 26/06/2019

Artigo aceito para publicação em: 09/09/2019 